\title{
EFEITOS DE POLÍMEROS ANIÔNICOS, DOS ADITIVOS SÓLIDOS E DO POTENCIAL ZETA NO COMPORTAMENTO REOLÓGICO DE SUSPENSÕES
}

\author{
D. R. NASCIMENTO ${ }^{1}$, B. R. OLIVEIRA ${ }^{1}$, S. C. MAGALHÃES FILHO ${ }^{1}$, E. C. H. PARAÍSO ${ }^{1}$, \\ C. M. SCHEID ${ }^{1}$, L. A. CALÇADA ${ }^{1 *}$ \\ ${ }^{1}$ Universidade Federal Rural do Rio de Janeiro, Departamento de Engenharia Química \\ *e-mail: calcada@ufrrj.br
}

\begin{abstract}
RESUMO
As propriedades de escoamento dos fluidos de perfuração dependem das características da fase dispersante e da fase dispersa. Por meio de fatores como polímeros viscosificantes, material particulado como sólidos adensantes e obturantes, entre outros aditivos, é possível controlar o comportamento reológico dos fluidos. Este controle nas propriedades dos fluidos de perfuração tem a finalidade de garantir o seu alto desempenho. Neste trabalho, pretende-se avaliar a influência dos polímeros carboximetilcelulose e goma xantana e o efeito do tipo e do tamanho das partículas como a barita, a calcita e a esfera de vidro no comportamento reológico de suspensões. Os resultados mostraram que a escolha do polímero, o tipo e o tamanho das partículas e o potencial zeta das suspensões influenciaram no perfil das curvas de escoamento e de viscosidade dos fluidos avaliados.
\end{abstract}

\section{INTRODUÇÃO}

Os fluidos de perfuração são sistemas líquidos multifásicos, formados por misturas de sólidos em suspensão, polímeros dissolvidos em água, entre outros compostos. A composição do fluido de perfuração é selecionada de modo a alcançar as propriedades desejadas com a finalidade de assegurar uma perfuração rápida e segura. A proporção entre os componentes básicos e as interações entre eles provocam sensíveis modificações nas propriedades físicoquímicas do fluido de perfuração. Consequentemente, a composição é o principal fator a considerar no controle de suas propriedades (THOMAS, 2001). Desse modo, é importante controlar as propriedades reológicas do fluido visando aperfeiçoar a operação de perfuração e minimizar a invasão do fluido através das formações (VITAL, 2005).
De acordo com Ortega et al. (1997), os maiores contribuintes para o comportamento reológico de uma suspensão são as propriedades e características do sólido e do fluido base. Entre os fatores que influenciam a reologia do sistema estão: concentração de sólidos, características do meio líquido (como densidade e viscosidade), temperatura, características físicas das partículas (como distribuição granulométrica, densidade, forma, área superficial específica etc.), tipo de interação entre as partículas (repulsão, atração), concentração de moléculas dispersantes no meio líquido, massa molar e conformação espacial da molécula de aditivos como dispersantes, espessura da camada de moléculas de dispersante adsorvidas em torno das partículas.

Buranasrisak \& Narasingha (2012) estudaram suspensões à base de água constituídas de carboximetilcelulose $(0,05 \%)$, naftaleno formaldeído sulfonato $(0,5 \%)$ e de 
partículas de carvão com tamanhos distintos. Os autores concluíram que os fluidos constituídos com os sólidos mais finos apresentaram maiores valores de viscosidade aparente com o aumento da taxa de deformação para uma mesma concentração de sólidos.

Verma et al. (2006) avaliaram suspensões à base de água e cinzas (subproduto da queima do carvão) com tamanhos diferentes. Eles constataram que à medida que houve redução do tamanho das partículas de cinza, as suspensões apresentaram um aumento nos valores de tensão limite de escoamento e viscosidade plástica relativa de Bingham. Segundo os autores, esse comportamento deve-se ao aumento do número de partículas por unidades de área e volume, o que ocasiona um acréscimo nas interações entre as partículas, resultando no aumento da resistência ao escoamento.

Omland et al. (2005) concluíram que uma distribuição de tamanho de partículas compostas por partículas finas aumenta a viscosidade da suspensão independentemente do tipo de partícula.

Olhero \& Ferreira (2004) observaram que o comportamento reológico das suspensões não pode ser explicado somente com base no tamanho da partícula. A distribuição do tamanho das partículas desempenha o papel mais relevante, uma vez que influencia diretamente a capacidade de empacotamento das partículas nas suspensões.

Mangesana et al. (2008) estudaram suspensões à base de água empregando três amostras de sílica $\left(\mathrm{SiO}_{2}\right)$ com distintos diâmetros de partícula. Eles constataram que a tensão cisalhante e a viscosidade aparente das suspensões aumentaram à medida que houve o aumento do tamanho das partículas de sílica. Eles atribuíram esse comportamento ao chamado "efeito inercial", no qual as partículas de tamanhos maiores apresentam maior inércia, requerendo maior tensão cisalhante para que ocorra o escoamento. Este comportamento contradiz a discussão apresentada por Verma et al. (2006).

Este trabalho visa avaliar a influência dos polímeros carboximetilcelulose e goma xantana e o efeito do tipo e do tamanho das partículas de barita, calcita e esfera de vidro (selecionadas em diferentes faixas de distribuição granulométrica) no comportamento reológico de suspensões tipicamente presentes em fluidos de perfuração.

\section{MATERIAL E MÉTODOS}

Neste trabalho, foi avaliado o efeito dos polímeros carboximetilcelulose e goma xantana e a influência do tipo e do tamanho das partículas de barita, calcita e esfera de vidro no comportamento reológico de suspensões. As seguintes técnicas analíticas foram adotadas: difratometria de raios $\mathrm{X}$, análise granulométrica por difração a laser, microscopia eletrônica de varredura, teste reológico e potencial zeta.

\subsection{Difratometria de raios $X$}

A técnica de difração de raios $\mathrm{X}$ foi utilizada para caracterizar os materiais empregados. Os difratogramas de raios $\mathrm{X}$ foram obtidos em um equipamento Rigaku Miniflex operando a $30 \mathrm{kV}$ e $15 \mathrm{~mA}$ com radiação de Co $\mathrm{K} \alpha$. A varredura foi conduzida de 1,1 a $60^{\circ}(2 \theta)$ com intervalos de $0,050^{\circ}$ e tempo de aquisição de $2 \mathrm{~s}$.

\subsection{Análise granulométrica por difração a laser}

Para a caracterização do tamanho dos sólidos foi empregado um analisador de partículas Malvern Mastersizer Hydro 2000 UM.

\subsection{Preparo das soluções e suspensões}

Os fluidos foram preparados com diferentes distribuições granulométricas de 
barita, bentonita branca, bentonita creme, calcita e esfera de vidro empregando diferentes tipos de polímeros.

Primeiramente, foram preparadas soluções com os polímeros carboximetilcelulose (CMC) e goma xantana (GX) hidratadas com 5,6L de água deionizada $(\mathrm{pH} \approx 7)$ sob alta agitação $(1700 \mathrm{rpm})$ no misturador Fisatom até a completa homogeneização. Em seguida, o volume foi completado com a água deionizada até que fossem atingidos $7 \mathrm{~L}$, permanecendo sob agitação por $10 \mathrm{~min}$. Foram adicionados 17,5 $\mathrm{mL}(0,25 \%$ em volume $)$ do bactericida glutaraldeído (marca Vetec) para retardar a degradação das soluções.

Após o preparo das soluções, os fluidos foram pesados em uma balança de lama Fann modelo 140, para que fosse determinada a quantidade de sólido necessária para alcançar a densidade desejada.

Diferentes suspensões foram preparadas com um volume de $350 \mathrm{~mL}$ empregando diferentes sólidos (barita, bentonita branca, bentonita creme, calcita, carbonato de cálcio ou esfera de vidro) selecionados em diferentes faixas granulométricas. Os fluidos foram projetados para atingirem densidade de $1,14 \mathrm{~g} / \mathrm{cm}^{3}$. A Tabela 1 apresenta as formulações empregadas para o preparo das suspensões.

\subsection{Caracterização dos fluidos}

As suspensões preparadas foram caracterizadas através da determinação dos seguintes parâmetros: $\mathrm{pH}$, concentração de sólidos (Cs), fração volumétrica de sólidos (s) e densidade $(\rho)$.

\subsection{Reologia}

Os testes reológicos a $25^{\circ} \mathrm{C}$ foram realizados em um reômetro Haake RheoStress 1 da Thermo Scientific, empregando a geometria do tipo cilindros coaxiais utilizando copo de medição DG43 e rotor cilíndrico DG43-Ti. Os ensaios foram realizados com taxa de deformação controlada, variando no intervalo de 0 a $1021 \mathrm{~s}^{-1}$ com duração de 120 s.

Tabela 1 - Formulação das suspensões.

\begin{tabular}{cccc}
\hline Componentes & \multicolumn{2}{c}{ Concentração } & Função \\
\hline Água deionizada & QSP* & - & Base \\
CMC & 2 & $\mathrm{lb} / \mathrm{bbl}$ & Viscosificante \\
Goma xantana & 2 & $\mathrm{lb} / \mathrm{bbl}$ & Viscosificante \\
Barita & QSP & - & Adensante/Obturante \\
Calcita & QSP & - & Adensante/Obturante \\
Esfera de vidro & QSP & - & Adensante/Obturante \\
Glutaraldeído & QSP & - & Bactericida \\
\hline *QSP: quantidade suficiente para 350mL de suspensão. \\
*CMC: carboximetilcelulose.
\end{tabular}

\subsection{Tratamento estatístico}

A reprodutibilidade das medidas de tensão de cisalhamento foi testada. A amostra do tipo CMC/barita $(0-71 \mu \mathrm{m})$ foi avaliada no Reômetro RheoStress 1 e foi selecionada para ser reproduzida em triplicata. Cada resultado foi comparado diretamente com outro, uma vez que eles foram medidos nas mesmas taxas de cisalhamento. Cada grupo de tensão de cisalhamento apresentou distribuição normal, portanto foi possível aplicar o teste estatístico $t$ de Student (teste t) e garantir que cada amostra foi estatisticamente a mesma, ou seja, o teste $\mathrm{t}$ devia demonstrar se as três amostras foram efetivamente réplicas. $O$ software STATISTICA foi empregado para realizar cada teste.

\subsection{Potencial zeta}

O potencial zeta é uma medida da magnitude da repulsão ou da atração eletrostática das cargas das partículas na suspensão. As medidas de potencial zeta foram realizadas no equipamento Malvern Zetasizer Nano series. Foi pesado $0,5 \mathrm{~g}$ de amostra para $50 \mathrm{~mL}$ de solução de $\mathrm{KCl} 0,001$ M.

\subsection{Microscopia eletrônica de varredura}


A microscopia eletrônica de varredura é utilizada para caracterizar os sólidos selecionados através de imagens que permitem a visualização da forma, da distribuição e das dimensões dos grãos, fibras e lâminas. Foi utilizado um microscópio eletrônico de varredura Hitachi Tabletop Microscope TM-1000.

\section{RESULTADOS E DISCUSSÃO}

\subsection{Caracterização mineralógica}

Os difratogramas de raios $\mathrm{X}$ da barita $\mathrm{e}$ dos polímeros CMC e GX são mostrados na Figura 1. Esta análise revelou que a barita apresenta em sua composição química $o$ sulfato de bário $\left(\mathrm{BaSO}_{4}\right)$ e a sílica (quartzo $\mathrm{SiO}_{2}$ ). O CMC é caracterizado por único pico em $2 \theta$ a aproximadamente $20^{\circ}$ (SARTOR et al., 2012). O polímero GX apresentou conformação amorfa.

A composição química dos sólidos barita e calcita é mostrada na Tabela 2 .

Figura 1 - Difratogramas de raios $\mathrm{X}\left(\mathrm{B}: \mathrm{BaSO}_{4}\right.$, Q: quartzo).

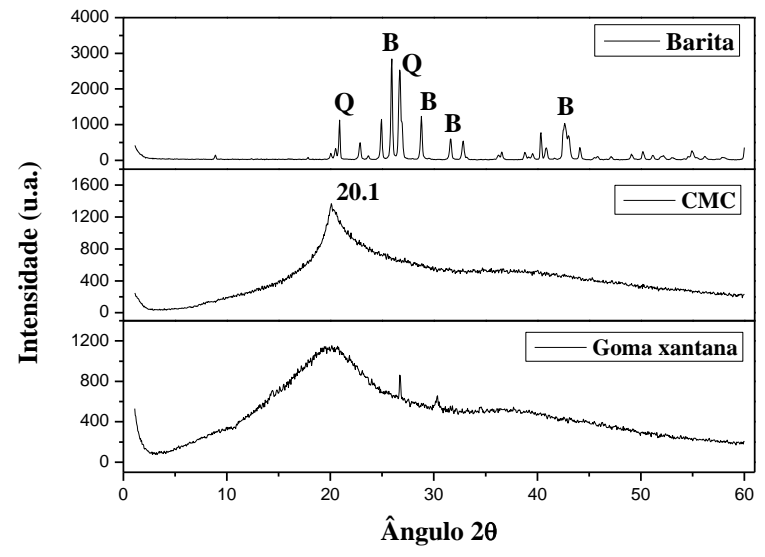

\subsection{Caracterização granulométrica}

Os parâmetros obtidos na caracterização de tamanho dos sólidos são mostrados na Tabela 3. $\mathrm{D}_{10}$ é igual ao diâmetro de partícula abaixo do qual se situam $10 \%$ das partículas, $\mathrm{D}_{50}$ é igual diâmetro de partícula abaixo do qual se situam $50 \%$ das partículas (considerado como diâmetro médio das partículas), $\mathrm{D}_{90}$ é igual ao diâmetro de partícula abaixo do qual se situam $90 \%$ das partículas e Dp é o diâmetro médio de Sauter, que representa a média dos diâmetros de esferas de área superficial igual ao das partículas reais.

Tabela 2 - Composição química dos sólidos.

\begin{tabular}{ccc}
\hline \multirow{2}{*}{ Espécie } & \multicolumn{2}{c}{ Teor $(\%)$} \\
\cline { 2 - 3 } & Buímica & Calcita \\
\hline $\mathrm{BaSO}_{4}$ & 71,3 & - \\
$\mathrm{SiO}_{2}$ & 25,25 & 3,61 \\
$\mathrm{Al}_{2} \mathrm{O}_{3}$ & 0,98 & 0,12 \\
$\mathrm{Fe}_{2} \mathrm{O}_{3}$ & 0,94 & 0,06 \\
$\mathrm{MgO}$ & - & 2,86 \\
$\mathrm{CaO}$ & - & 54,5 \\
$\mathrm{CaCO}$ & - & 38,85 \\
Outros & 1,53 & - \\
\hline
\end{tabular}

Tabela 3 - Caracterização dos sólidos.

\begin{tabular}{ccccc}
\hline Material & $\begin{array}{c}\mathbf{D}_{\mathbf{1 0}} \\
(\boldsymbol{\mu m})\end{array}$ & $\begin{array}{c}\mathbf{D}_{\mathbf{5 0}} \\
(\boldsymbol{\mu m})\end{array}$ & $\begin{array}{c}\mathbf{D}_{\mathbf{9 0}} \\
(\boldsymbol{\mu m})\end{array}$ & $\begin{array}{c}\mathbf{D p} \\
(\boldsymbol{\mu m})\end{array}$ \\
\hline $\begin{array}{c}\text { Barita } \\
(0-71 \mu \mathrm{m})\end{array}$ & 3,46 & 19,99 & 44,04 & 7,40 \\
$\begin{array}{c}\text { Barita } \\
(61-317 \mu \mathrm{m})\end{array}$ & 100,96 & 141,15 & 198,67 & 136,66 \\
$\begin{array}{c}\text { Calcita } \\
(0-83 \mu \mathrm{m})\end{array}$ & 2,91 & 21,06 & 49,25 & 6,38 \\
$\quad \begin{array}{c}\text { Calcita } \\
(65-369 \mu \mathrm{m})\end{array}$ & 98,58 & 148,85 & 221,36 & 89,68 \\
$\begin{array}{c}\text { Esfera de vidro } \\
(14-83 \mu \mathrm{m})\end{array}$ & 24,67 & 37,22 & 55,69 & 35,36 \\
$\begin{array}{c}\text { Esfera de vidro } \\
(53-272 \mu \mathrm{m})\end{array}$ & 86,62 & 120,73 & 168,97 & 116,91 \\
\hline
\end{tabular}

\subsection{Caracterização das suspensões}

Nas Tabelas 4 e 5 são apresentados os valores de $\mathrm{pH}$, de concentração de sólidos (Cs), de fração volumétrica de sólidos (s) e de densidade $(\rho)$ das suspensões preparadas com CMC e GX, respectivamente.

\subsection{Estudo reológico}

3.4.1 Suspensões de barita 
As Figuras 2 e 3 apresentam as curvas de escoamento e de viscosidade para a barita em suspensão de CMC e solução de CMC em água. Os resultados mostraram que a redução do tamanho das partículas de barita promoveu um pequeno aumento nos valores de tensão cisalhante e viscosidade aparente da suspensão. Não foi possível constatar uma modificação pronunciada no comportamento reológico da suspensão com a redução do tamanho das partículas de barita. Esse comportamento foi igualmente observado nas suspensões de GX e barita.

Tabela 4 - Caracterização das suspensões de CMC.

\begin{tabular}{ccccc}
\hline Suspensões & $\mathbf{p H}$ & $\mathbf{\rho}\left(\mathbf{g} / \mathbf{c m}^{\mathbf{3}}\right)$ & $\mathbf{C s}(\mathbf{g} / \mathbf{l})$ & $\mathbf{s}$ \\
\hline $\begin{array}{c}\text { CMC + barita } \\
(0-71 \mu \mathrm{m})\end{array}$ & 9,27 & 1,10 & 221 & 0,06 \\
$\begin{array}{c}\text { CMC + barita } \\
(61-317 \mu \mathrm{m})\end{array}$ & 9,08 & 1,09 & 239 & 0,07 \\
$\begin{array}{c}\text { CMC + calcita } \\
(0-83 \mu \mathrm{m})\end{array}$ & 9,04 & 1,15 & 275 & 0,10 \\
$\begin{array}{c}\mathrm{CMC}+\text { calcita } \\
(65-369 \mu \mathrm{m})\end{array}$ & 9,14 & 1,13 & 253 & 0,09 \\
$\begin{array}{c}\mathrm{CMC}+\text { esfera de } \\
\text { vidro }(14-83 \mu \mathrm{m})\end{array}$ & 9,94 & 1,13 & 276 & 0,10 \\
$\begin{array}{c}\text { CMC + esfera de } \\
\text { vidro }(53-272 \mu \mathrm{m})\end{array}$ & 9,74 & 1,11 & 282 & 0,10 \\
\hline *suspensão com $25 \%$ em massa de sólido. & &
\end{tabular}

Tabela 5 - Caracterização das suspensões de GX.

\begin{tabular}{ccccc}
\hline Suspensões & $\mathbf{p H}$ & $\mathbf{\rho}\left(\mathbf{g} / \mathbf{c m}^{3}\right)$ & $\mathbf{C s}(\mathbf{g} / \mathbf{l})$ & $\mathbf{s}$ \\
\hline $\begin{array}{c}\text { GX + barita } \\
(0-71 \mu \mathrm{m})\end{array}$ & 7,96 & 1,14 & 256 & 0,08 \\
$\begin{array}{c}\text { GX + barita } \\
(61-317 \mu \mathrm{m})\end{array}$ & 7,80 & 1,10 & 260 & 0,08 \\
$\begin{array}{c}\text { GX + calcita } \\
(0-83 \mu \mathrm{m})\end{array}$ & 8,44 & 1,08 & 290 & 0,11 \\
$\begin{array}{c}\text { GX + calcita } \\
(65-369 \mu \mathrm{m})\end{array}$ & 8,43 & 1,07 & 286 & 0,11 \\
$\begin{array}{c}\text { GX + esfera de } \\
\text { vidro }(14-83 \mu \mathrm{m})\end{array}$ & 9,10 & 1,13 & 288 & 0,10 \\
$\begin{array}{c}\text { GX + esfera de } \\
\text { vidro }(53-272 \mu \mathrm{m})\end{array}$ & 8,63 & 1,15 & 290 & 0,10 \\
\hline *suspensão com $25 \%$ em massa de sólido. & &
\end{tabular}

\subsubsection{Suspensões de calcita}

As Figuras 4 e 5 apresentam as curvas de escoamento e as curvas de viscosidade das suspensões preparadas com CMC e calcita. A suspensão de partículas finas de calcita apresentou um aumento nos valores de tensão cisalhante e viscosidade aparente em comparação com a suspensão formulada com partículas maiores de calcita. Esse comportamento pode explicado pelo aumento das interações entre as partículas, pois há um número maior de partículas por unidades de área e volume com a redução do tamanho das partículas, o que promove um acréscimo na resistência ao fluxo.

Figura 2 - Tensão de cisalhamento versus taxa de deformação (suspensões CMC/barita).

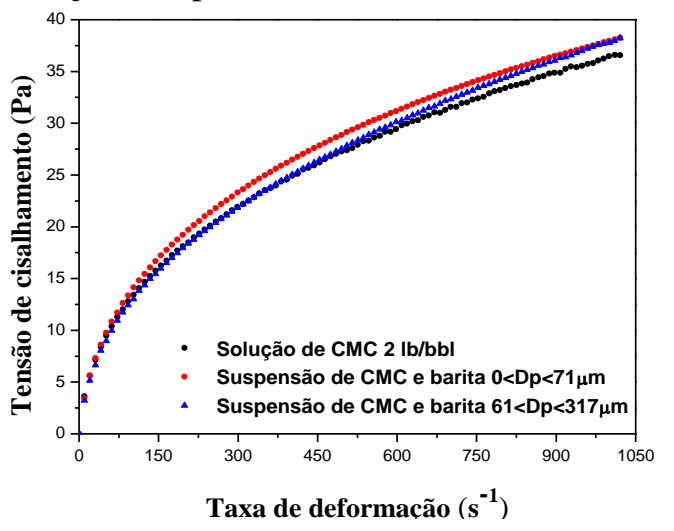

Figura 3 - Viscosidade aparente versus taxa de deformação (suspensões CMC/barita).

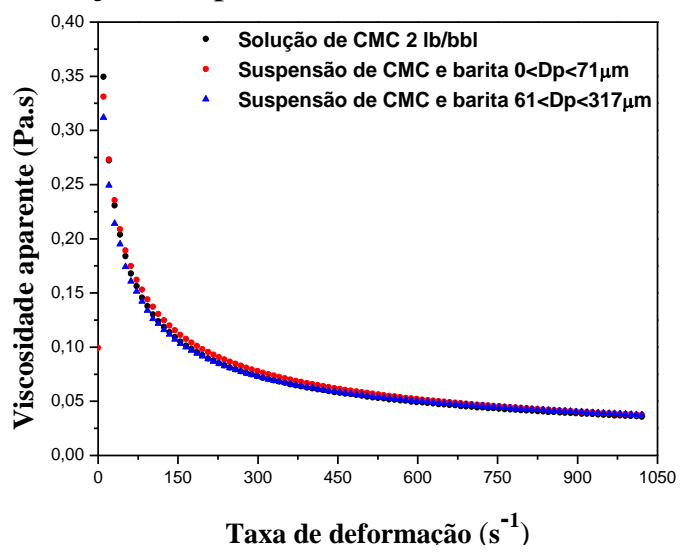

As Figuras 6 e 7 apresentam as curvas de escoamento e as curvas de viscosidade das suspensões de GX/calcita. Os resultados mostraram que a redução do tamanho das partículas de calcita promoveu um pequeno aumento nos valores de tensão cisalhante da suspensão. Porém, as curvas de viscosidade dessas suspensões não apresentaram diferenças, conforme mostrado na Figura 13. Não houve modificação no comportamento 
reológico das suspensões com a redução do tamanho das partículas de calcita. As suspensões de calcita e GX apresentaram tensões limites de escoamento próximas a 7 $\mathrm{Pa}$.

Figura 4 - Tensão de cisalhamento versus taxa de deformação (suspensões CMC/calcita).

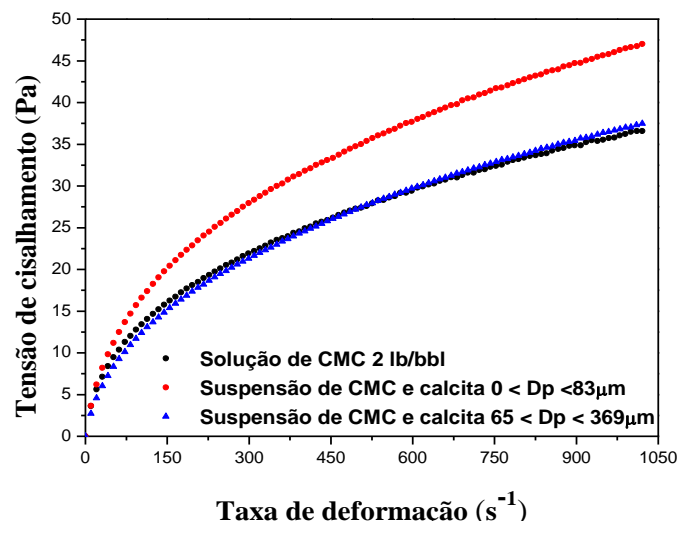

Figura 5 - Viscosidade aparente versus taxa de deformação (suspensões CMC/calcita).

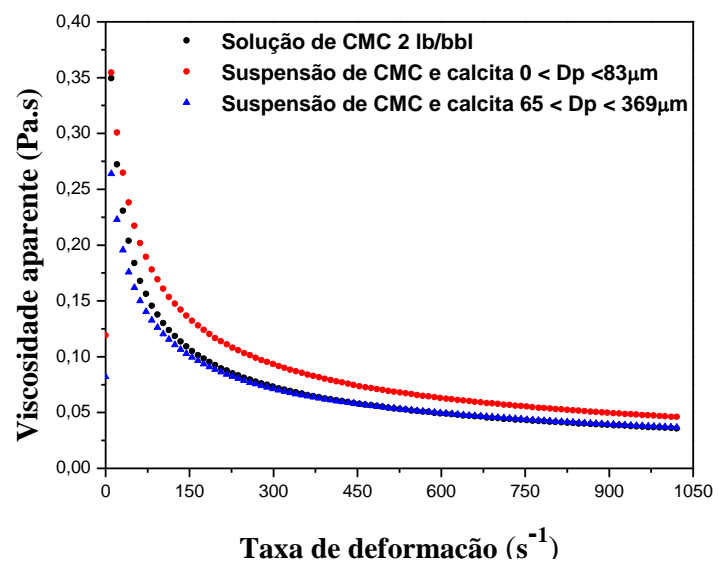

3.4.3 Suspensões de esfera de vidro

A suspensão de CMC e partículas finas de esfera de vidro apresentou um pequeno aumento nos valores de tensão em comparação com a suspensão formulada com partículas maiores de esfera de vidro, conforme mostrado na Figura 8.

As suspensões com GX e esfera de vidro apresentaram maiores valores de tensão de cisalhamento com o aumento do tamanho da partícula, conforme mostrado na Figura 10. Além disso, essas suspensões apresentaram tensões limites de escoamento próximas a 7 $\mathrm{Pa}$. As curvas de viscosidade das suspensões de CMC e GX com esfera de vidro não foram influenciadas pela mudança do tamanho das partículas de esferas de vidro, conforme mostrado nas Figuras 9 e 11.

Figura 6 - Tensão de cisalhamento versus taxa de deformação (suspensões GX/calcita).

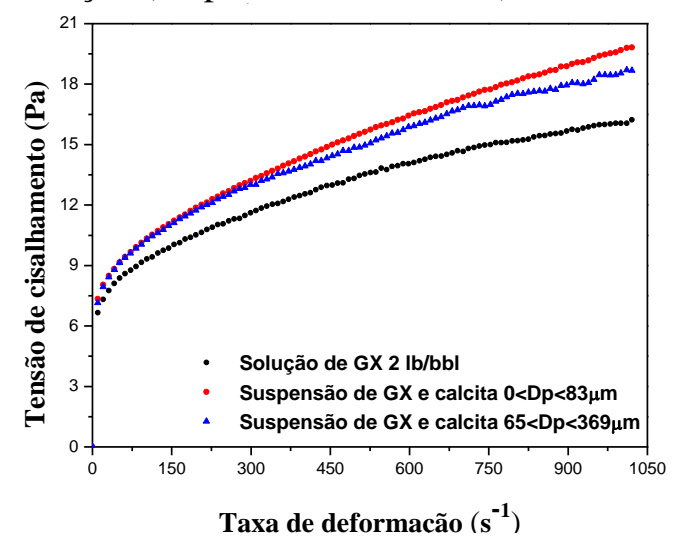

Figura 7 - Viscosidade aparente versus taxa de deformação (suspensões GX/calcita).

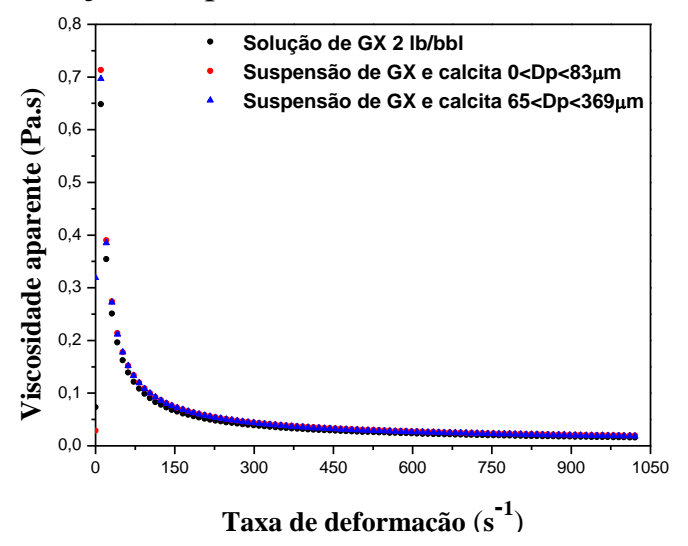

Figura 8 - Tensão de cisalhamento versus taxa de deformação (suspensões CMC/esfera de vidro).

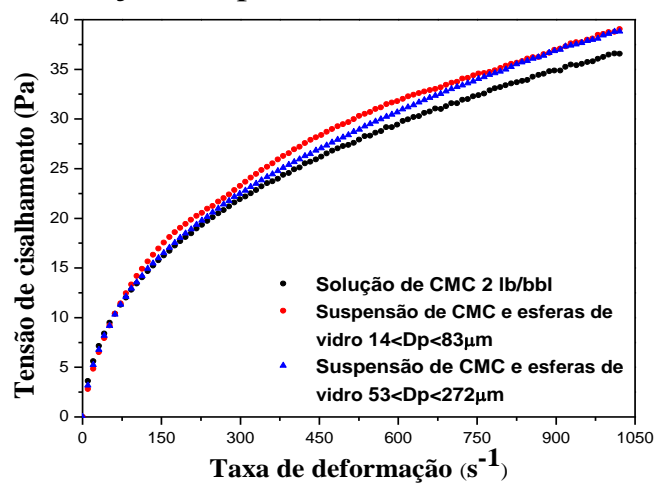


Figura 9 - Viscosidade aparente versus taxa de deformação (suspensões CMC/esfera de vidro).

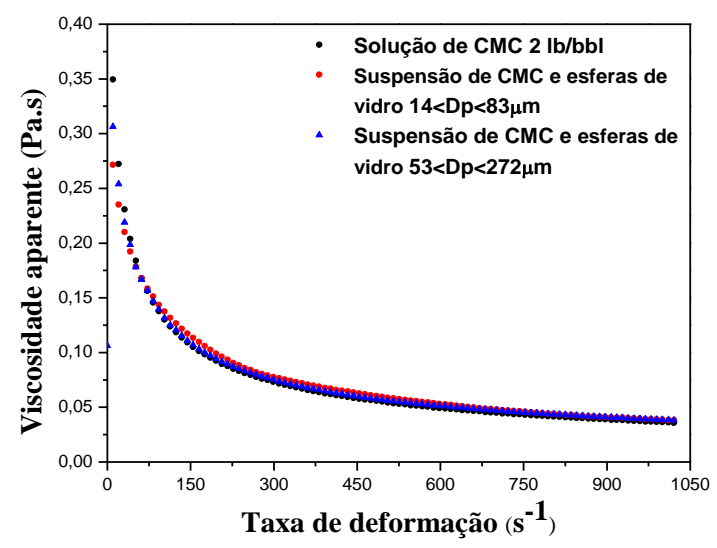

Figura 10 - Tensão de cisalhamento versus taxa de deformação (suspensões GX/esfera de vidro).

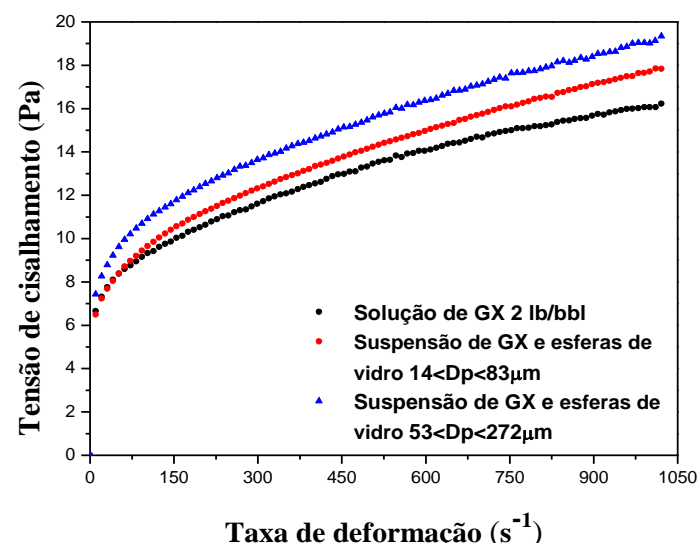

Figura 11 - Viscosidade aparente versus taxa de deformação (suspensões GX/esfera de vidro).

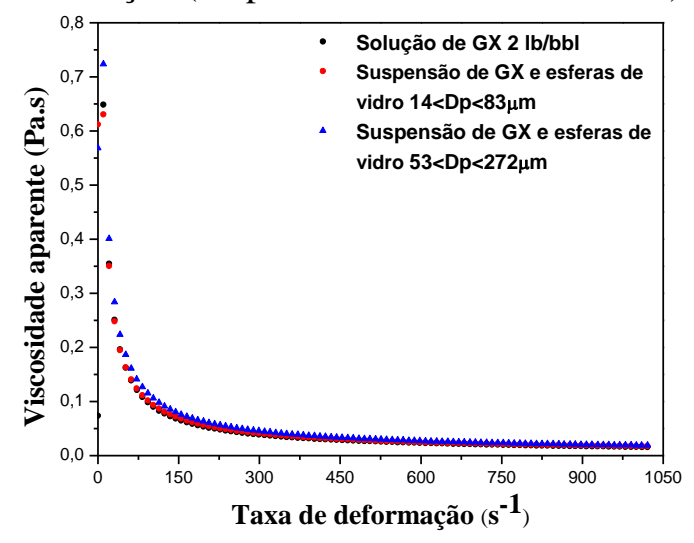

A Tabela 6 apresenta os resultados estatísticos do teste t. Pode ser visto que os valores de p-valor foram maiores do que 0,05 , condição na qual não deve-se rejeitar a hipótese de nulidade, a qual afirmou que as tensões cisalhantes, em média, são iguais. Portanto, é possível concluir (dentro de um nível de confiança de 95\%) que todas as amostras apresentadas são estatisticamente similares.

Tabela 6. Resultados estatísticos do teste t.

\begin{tabular}{cc}
\hline Variáveis & p-valor \\
\hline Tensão cisalhante 1 x Tensão cisalhante 2 & 0,7749 \\
Tensão cisalhante 1 x Tensão cisalhante 3 & 0,5554 \\
Tensão cisalhante 2 x Tensão cisalhante 3 & 0,7430 \\
\hline
\end{tabular}

Portanto, não foi necessário preparar triplicatas de cada tipo de suspensão, uma vez que somente uma amostra é suficiente para assegurar estatisticamente a validade das medidas de tensão de cisalhamento, devido a baixa margem de erros experimentais.

As medidas de potencial zeta das suspensões formuladas com CMC e GX e partículas finas de barita, calcita e esfera de vidro são apresentadas na Tabela 7.

Tabela 7 - Potencial zeta das suspensões.

\begin{tabular}{cc}
\hline Suspensões & Potencial zeta $(\mathbf{m V})$ \\
\hline CMC + barita $(0-71 \mu \mathrm{m})$ & $-55,40$ \\
CMC + calcita $(0-83 \mu \mathrm{m})$ & $-39,40$ \\
CMC + esfera de vidro $(14-83 \mu \mathrm{m})$ & $-61,10$ \\
GX + barita $(0-71 \mu \mathrm{m})$ & $-48,0$ \\
GX + calcita $(0-83 \mu \mathrm{m})$ & $-47,70$ \\
GX + esfera de vidro $(14-83 \mu \mathrm{m})$ & $-51,0$ \\
\hline *CMC: carboximetilcelulose. & \\
*GX: goma xantana.
\end{tabular}

Segundo Garcia et al. (2003) o aumento do potencial zeta promove o reforço da barreira eletrostática repulsiva, promovendo uma redução das forças de atração entre as partículas, isto é, diminuindo das interações entre as partículas na suspensão, resultando em uma menor resistência ao fluxo e, consequentemente, em menor viscosidade da suspensão. 


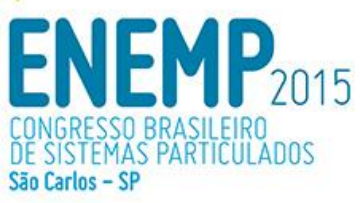

Este comportamento pode observado nas suspensões formuladas com CMC, GX e partículas finas de barita, calcita e esfera de vidro, conforme mostrado nas Figuras $12 \mathrm{e}$ 13. As suspensões de calcita apresentaram menores medidas (em módulo) de potencial zeta e maiores valores de viscosidade aparente, indicando que há repulsão entre as partículas de calcita na suspensão, porém não mais intensa do que as presentes nas suspensões de barita e esfera de vidro, conforme mostrado na Tabela 7. Dessa forma, as suspensões com barita e esfera de vidro apresentaram menores valores de viscosidade aparente, já que houve um maior reforço barreira eletrostática repulsiva nessas suspensões evidenciado pelas maiores medidas (em módulo) de potencial zeta, resultando em uma menor interação entre as partículas e, consequentemente, em menor resistência ao fluxo e menor viscosidade aparente.

Figura 12 - Viscosidade aparente versus taxa de deformação (suspensões de CMC).

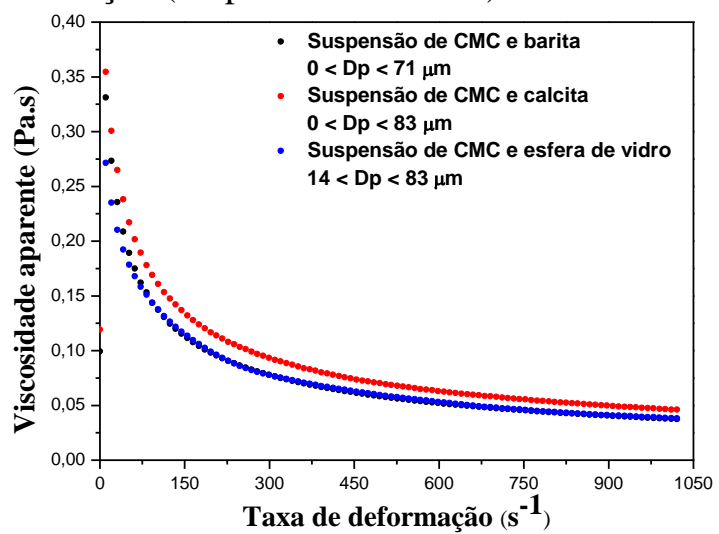

\subsection{Análise de imagem}

Nas Figuras de 14 a 19 são apresentadas as micrografias das tortas das suspensões formuladas. Estas imagens permitem avaliar as características microestruturais e morfológicas dessas suspensões.
Figura 13 - Viscosidade aparente versus taxa de deformação (suspensões de GX).

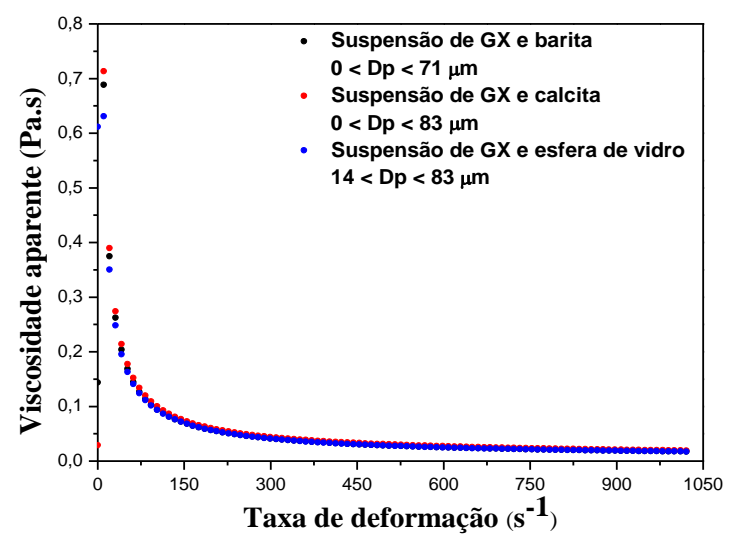

Figura 14 - Micrografia da torta da suspensão de CMC e barita $(0-71 \mu \mathrm{m})$ - ampliação 2500x.

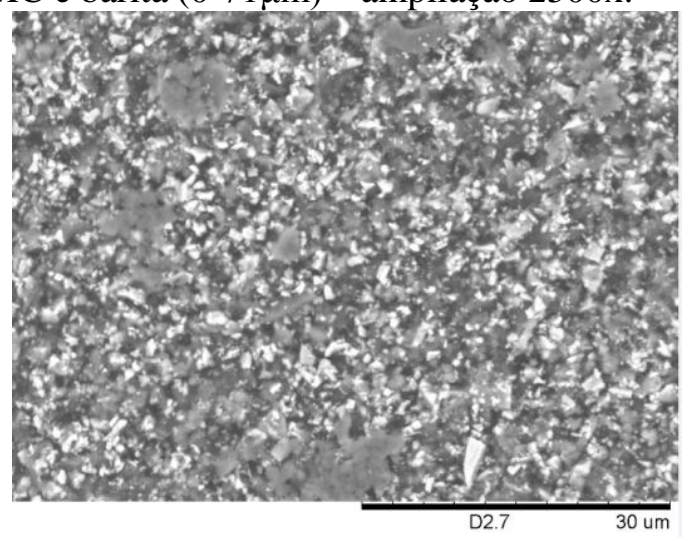

Figura 15 - Micrografia da torta da suspensão de

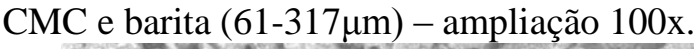

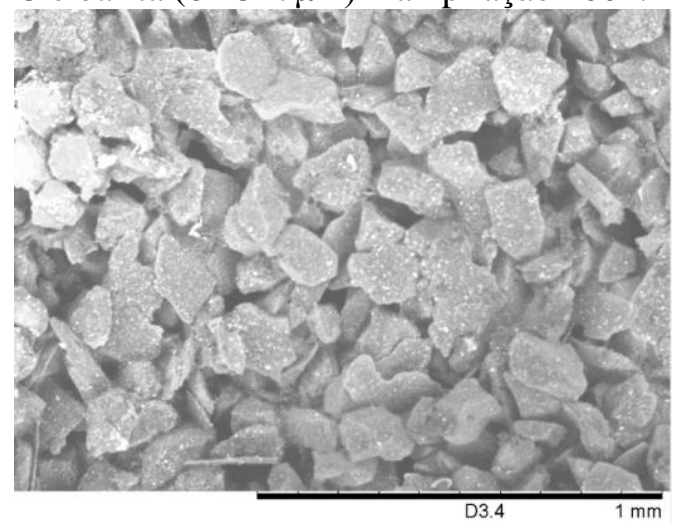


Figura 16 - Micrografia da torta da suspensão de CMC e calcita $(0-83 \mu \mathrm{m})$ - ampliação 300x.

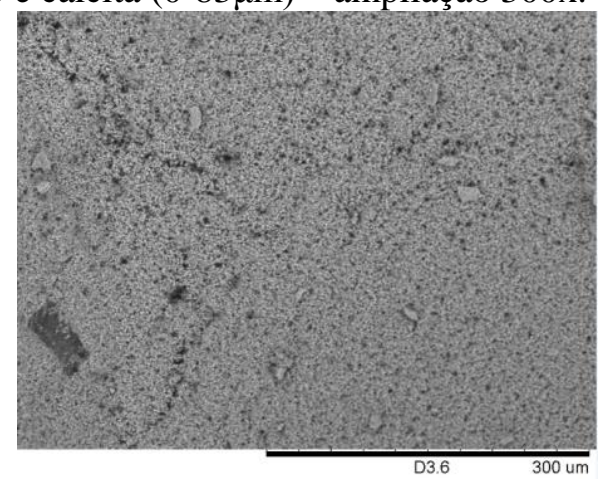

Figura 17 - Micrografia da torta da suspensão de

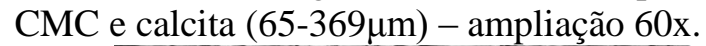

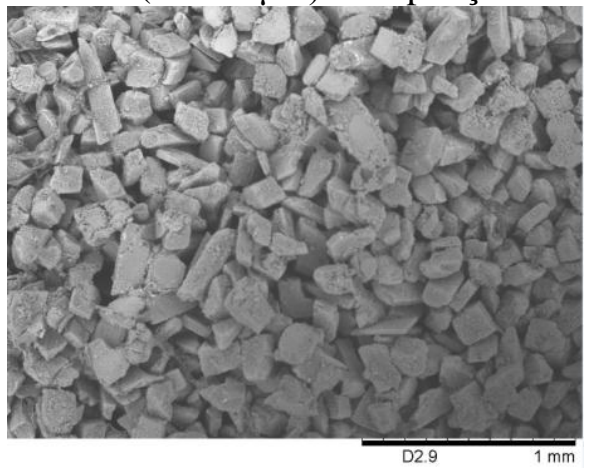

As micrografias revelaram que as partículas estão dispersas uniformemente nas suspensões. As partículas maiores de barita e calcita apresentaram formas irregulares, conforme mostrado nas Figuras 15 e 17.

Figura 18 - Micrografia da torta da suspensão de

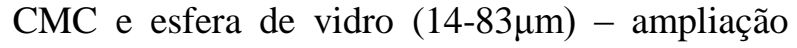
200x.

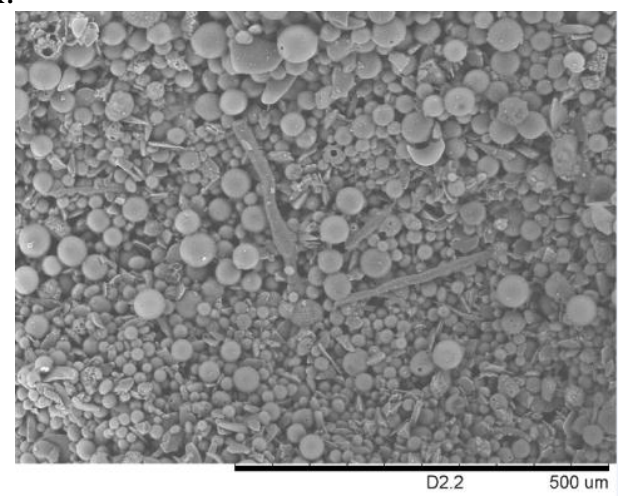

Figura 19 - Micrografia da torta da suspensão de CMC e esfera de vidro (53-272 $\mu \mathrm{m})$ - ampliação 120x.

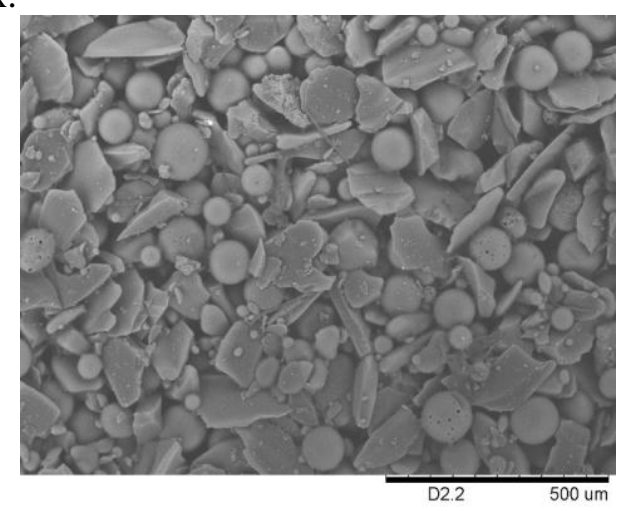

\section{CONCLUSÕES}

Os fluidos preparados com CMC precisaram de uma maior tensão de cisalhamento para escoar, devido a sua alta viscosidade aparente, quando comparado com as suspensões de GX.

Não foi possível constatar um efeito pronunciado do tamanho dos sólidos no comportamento reológico das suspensões de barita nas faixas granulométricas empregadas.

As faixas de distribuição granulométrica de calcita alteraram as curvas de escoamento e as curvas de viscosidade das suspensões de CMC. As suspensões de GX e calcita apresentaram tensões limites de escoamento.

As curvas de viscosidade das suspensões de esferas de vidro (com CMC e $\mathrm{GX}$ ) não foram influenciadas de forma pronunciada pela mudança das faixas granulométricas das partículas de esferas de vidro. As suspensões de GX e esfera de vidro apresentaram tensões limites de escoamento.

$\mathrm{O}$ aumento do potencial zeta promove uma diminuição das interações entre as partículas na suspensão, resultando em uma menor resistência ao fluxo e, consequentemente, menor viscosidade.

Mediante a análise dos resultados, observa-se que, em geral, a diminuição do diâmetro médio das partículas dos sólidos 
promoveu um aumento nos valores de tensão cisalhante das suspensões avaliadas.

\section{REFERENCIAS}

AMORIM, L. V. PEREIRA, M. S., FERREIRA, H. C., 2008. Anais do Rio Oil \& Gas Expo and Conf., Rio de Janeiro, RJ.

BURANASRISAK, P., NARASINGHA, M. $H$. Effects of particle size distribution and packing characteristics on the preparation of highly-loaded coal-water slurry. International Journal of Chemical Engineering an Applications, 3, 1, 31-35, 2012.

GARCIA, F., LE BOLAY, N., FRANCES, C. Rheological behaviour and related granulometric properties of dense aggregated suspensions during a ultrafine comminution process. Powder Technology, 130, 407-414, 2003.

MANGENASA, N., CHIKUSU, R. S., MAINZA, A. N. The effect of particle sizes and solids concentration on the rheology of silica sand based suspensions. The journal of the southem african institute of Mining and Metarllurgy, 108, 237-243, 2008.

OLHERO, S. M., FERREIRA J. M. F. Influence of particle distribution on rheology and particle packing of silica based suspensions. Powder Technology, 139, 60-75, 2004.

OMLAND, T. H., DAHL, B., SAASEN, A., SVANES, K., AMUNDSEN, P. A. The influence of particle type and size distribuition on viscosity in a nonNewtonian drilling fluid. Annual Transactions of the Nordic Rheology Society, 13, 2005.
ORTEGA, F. S., PADOLFELLI, V.C., RODRIGUES, J. A., SOUZA, D. P. F. Aspectos da reologia e da estabilidade de suspensões. Parte I: fundamentos. Revista Cerãmica, v. 43, 1997.

SARTOR, G.B., EVSSEV, I., BURGARDT, V. C. F., OLIVEIRA, D. F., 2012. Uso da técnica de difração de raios-X para avaliação da interação de biopolímeros. Sicite XVII.

THOMAS J. E. Fundamentos de Engenharia de Petróleo. 2001. Rio de Janeiro: PETROBRAS, 271 p.

VITAL, G. S. Seleção de tensoativos e influência de um estabilizante para a otimização de formulações de fluidos de perfuração à base de óleo vegetal. 2005 (Monografia de fim de Curso). Natal: UFRN, $50 \mathrm{p}$.

VERMA, A. K., SINGH, S. N., SESHADRI, $V$. Effect of particle size distribution on rheological properties of fly ash slurries at high concentrations, International Journal of Fluid Mechanics, 33, 5, 445-457, 2006.

\section{AGRADECIMENTOS}

Os autores gentilmente agradecem ao apoio financeiro da CENPES/PETROBRAS e PPGEQ/UFRRJ. 